\title{
ROLE OF HYSTEROSCOPIC GUIDED ENDOMETRIAL BIOPSY IN DIAGNOSIS OF ENDOMETRIAL PATHOLOGY IN PATIENTS WITH UNEXPLAINED RECURRENT IMPLANTATION FAILURE
}

By

\author{
Ahmed El-Sheikh, Hesham Abou Senna and Mohamed Hussein \\ Department of Obstetrics and Gynecology, Faculty of Medicine, Al-Azhar University \\ E-mail: $\underline{\text { dr_hasona@icloud.com }}$
}

\begin{abstract}
Background: Hysteroscopy is one of the most important investigations in women with recurrent implantation failure (RIF). It allows reliable visual assessment of the cervical canal and uterine cavity and it is considered to be the gold standard to diagnose intrauterine pathology and has minimal intra-operative and post-operative morbidity.
\end{abstract}

Objective: To evaluate the role of hysteroscopic guided endometrial biopsy in diagnosis of endometrial pathology in patients with unexplained recurrent implantation failure.

Patients and methods: This prospective study was done on 100 patients attended Sayed Galal Hospital from March 2018 to September 2019, with history of recurrent implantation failure.

All patients were evaluated by full history taking include (Personal, Menstrual, Obstetric, Past), Full clinical examination (General, Abdominal, Local), transvaginal ultrasound, hysteroscopy and biopsy. Samples were collected to be examined for histopathology to detect any disease and to be tabulated for computerized analysis.

Results: Of the 100 patients of infertility with a history of recurrent implantation failure undergoing endometrial biopsy guided by hysteroscopy, 48 (48\%) showed normal findings and 52 (52\%) showed abnormal findings: 28 were with normal hysteroscope but endometrial biopsy showed signs of chronic endometritis (28\%), 12 showed both abnormal hysteroscope and positive signs of chronic endometritis (12\%), 7 showed endometrial polyp (7\%), 4 showed fine intrauterine adhesions (4\%), and 1 showed cervical stenosis $(1 \%)$.

Conclusion: Hysteroscopy is of a great value in the evaluation and diagnosis of the endometrial pathology in patients with unexplained recurrent implantation failure.

Key words: IVF, Infertility, hysteroscope, biopsy, recurrent implantation failure, chronic endometritis.

\section{INTRODUCTION}

The endometrium is considered receptive during an individually defined period, the window of implantation (WOI), when the mother permits a blastocyst to attach and implant.
This individual receptivity status can now be objectively diagnosed using the endometrial receptivity array (ERA) (Katzorke et al., 2016).

Hysteroscopy is one of the most important investigations in women with 
recurrent implantation failure (RIF), it allows reliable visual assessment of the cervical canal and uterine cavity and it is considered to be the gold standard to diagnose intrauterine pathology and has Minimal intra-operative and postoperative morbidity (Coughlan et al., 2014).

Endometrial scratching, also known as endometrial injury, biopsy or trauma, is currently being proposed as a technique to increase the probability of implantation in women undergoing IVF, Endometrial injury or stimulation may cause a pseudodeicidal reaction that enhances implantation, Pregnancy and live birth rates in the IVF cycle following the biopsy were doubled (Nastri et al., 2013).

The most common indication for endometrial scratching was recurrent Implantation failure (RIF), the most common time frame for endometrial scratching was in the luteal phase of the cycle prior to the embryo transfer cycle (Wadhwa et al., 2015).

Hysteroscopy is considered as the definitive diagnostic tool to evaluate any abnormality suspected on hysterosalpingography, transvaginal ultrasound scan or saline hysterosonography during routine investigation of infertile patients, minimally invasive hysteroscope have minimized the pain experienced by patients during the procedure and made it feasible to use hysteroscopy as a routine outpatient examination, following recurrent IVF failure; there is some evidence of benefit from hysteroscopy in increasing the chance of pregnancy in the subsequent IVF cycle, both in those with abnormal and normal hysteroscopic findings various possible mechanisms have been proposed for this beneficial effect (El-Toukhy et al., 2016).

(Cicinelli et al., 2015) demonstrated that $\mathrm{CE}$ is a common finding in women complaining of repeated implantation failure and appropriate antibiotic treatment had improved significantly the rate of successful pregnancies, the reports suggest the presence of CE may alter endometrial receptivity and negatively affect fertility outcome.

Hysteroscopy is the only access route for direct visualization of the uterine cavity; previous publications confirmed that hysteroscopy without an endometrial biopsy has a low positive predictive value in the detection of endometritis. Endometrial biopsy has proven useful for the diagnosis of intrauterine inflammatory states. Hysteroscopy with endometrial biopsy is assumed to be the best method for the detection of intrauterine abnormalities that may interfere with implantation (Devroey et al. 2009).

The present work aimed to evaluate role of hysteroscopic guided endometrial biopsy in diagnosis of endometrial pathology in patients with unexplained recurrent implantation failure.

\section{PATIENTS AND METHODS}

In this prospective study, 100 patients who had undergone two or more failed IVF cycles, in which two or more goodquality embryos were transferred per procedure, participated prospectively in this study. All the participating patients had normal appearance of the uterine cavity on ultrasound and HSG, written consents were also taken from all of them before the study. 
Our inclusion criteria were females in the reproductive period between 25-40 years of age with recurrent unexplained implantation failure, normal ultrasound, normal HSG findings and good quality embryo.

We excluded those with male factor for infertility, first time IVF, abnormal ultrasound or abnormal HSG.

Hysteroscopy was performed under anesthesia in the proliferative phase of the cycle (between days 6-12) to exclude the possibility of disturbing spontaneously occurring pregnancy and for the advantage that the endometrium was thinner and its visibility is better.

Exploration of the uterine cavity was done after diagnostic hysteroscopy.A vaginal speculum was placed and endometrial biopsy with a pipelle aspiration was taken and the specimen was fixed in neutral formalin before being embedded in paraffin for histological analysis.

\section{Statistical methods:}

IBM SPSS statistics (V. 25.0, IBM Corp., USA, 2017-2018) was used for data analysis.

Data were expressed as Mean \pm SD for quantitative parametric measures in addition to both number and percentage for categorized data.

\section{The following tests were done:}

1. Descriptive statistics including mean; SD and Range.

2. Chi-square test to study the association between each 2 variables or comparison between 2 independent groups as regards the categorized data.

The probability of error at 0.05 was considered significant.

\section{RESULTS}

Of the 100 patients of infertility with a history recurrent implantation failure undergoing endometrial biopsy guided by hysteroscopy, 48 (48\%) showed normal findings and $52(52 \%)$ showed abnormal findings; the abnormal findings were as follows: 28 were with normal hysteroscope but endometrial biopsy show signs of chronic endometritis (28\%),12 show both abnormal hysteroscope and positive signs of chronic endometritis (12\%), 7 show endometrial polyp (7\%),4 show fine intrauterine adhesions (4\%), 1 show cervical stenosis $(1 \%)$.

Seventy two patients were presented with primary infertility $(72 \%)$ and 28 patients were presented with secondary infertility (28\%), 18 patients were presented with endometrial hyperemia under hysteroscope (18\%), 20 patients were presented with mucosal edema under hysteroscope $(20 \%), 16$ patients were presented with micropolyps under hysteroscope $(16 \%), 40$ patients were presented with chronic endometritis detected by histological biopsy (40\%), 24 patients were presented with uterine abnormality under hysteroscope (24\%), 12 patients were presented with uterine abnormality other than chronic endometritis (12\%): (7\%) endometrial polyp, (4\%) fine adhesions and (1\%) cervical stenosis (Table 1). 
Table (1): Presentation of studied patients

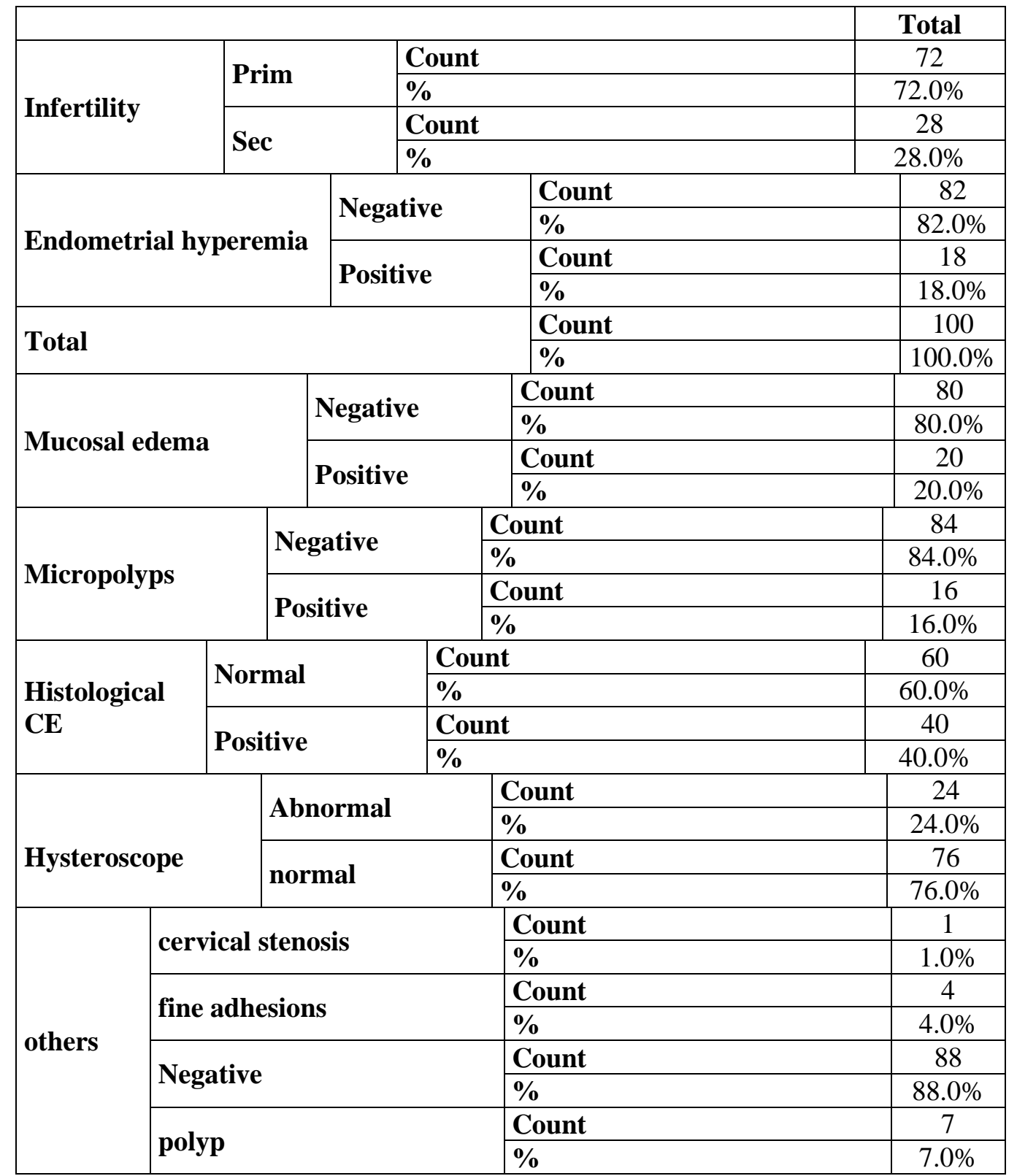

Fifty two patients were presented by signs of chronic endometritis under hysteroscope (Table 2).

Table (2): Incidence of chronic endometritis under hysteroscope.

\begin{tabular}{|c|c|c|c|}
\hline \multirow{5}{*}{$\begin{array}{l}\text { Hysteroscope + } \\
\text { CE }\end{array}$} & & & Total \\
\hline & \multirow{2}{*}{ Neg. } & Count & 48 \\
\hline & & $\%$ & $48.0 \%$ \\
\hline & \multirow{2}{*}{ Pos. } & Count & 52 \\
\hline & & $\%$ & $52.0 \%$ \\
\hline \multirow{2}{*}{\multicolumn{2}{|c|}{ Total }} & Count & 100 \\
\hline & & $\%$ & $100.0 \%$ \\
\hline
\end{tabular}

Hysteroscopic diagnosis of histological CE had $50 \%$ sensitivity, and $63.1 \%$ specificity (Table 3). 
Table (3): The sensitivity and specificity for diagnosis of histological CE under hysteroscopy

\begin{tabular}{|c|c|c|c|c|c|}
\hline & \multicolumn{2}{|c|}{ Hysteroscope } & \multirow{2}{*}{ Total } \\
\hline & & & Abnormal & normal & \\
\hline \multirow{4}{*}{$\begin{array}{l}\text { Histologi-cal } \\
\mathrm{CE}\end{array}$} & \multirow{2}{*}{ Normal } & Count & 12 & 48 & 60 \\
\hline & & $\%$ & $50.0 \%$ & $63.2 \%$ & $60.0 \%$ \\
\hline & \multirow{2}{*}{ Positive } & Count & 12 & 28 & 40 \\
\hline & & $\%$ & $50.0 \%$ & $36.8 \%$ & $40.0 \%$ \\
\hline \multirow{2}{*}{\multicolumn{2}{|c|}{ Total }} & Count & 24 & 76 & 100 \\
\hline & & $\%$ & $100.0 \%$ & $100.0 \%$ & $100.0 \%$ \\
\hline
\end{tabular}

\section{DISCUSSION}

The diagnosis of unexplained infertility was done when the following criteria were met: Normal ovulatory function was established by means of basal body temperature measurement, cervical mucus changes, serum luteinizing hormone (LH) surge or mid-luteal progesterone levels, or evidence of follicular rupture during ultrasound. Semen analysis was normal, tubal patency was established by hysterosalpingography, normal uterine cavity was established by transvaginal sonography and good quality embryo.

In our study, 100 cases with recurrent implantation failure were included; $72 \%$ had primary infertility and $28 \%$ had secondary infertility with no statistically significant difference between the two types of infertility. This agrees with Sahu et al. (2012) who found that there was no significant difference in the rate of uterine pathology between women with primary and secondary infertility.

In our study, diagnostic office hysteroscopy showed that $24 \%$ of cases with recurrent implantation failure had abnormal uterine findings and $76 \%$ of cases had normal uterine cavity; the most common hysteroscopic finding was signs of chronic endometritis $16-20 \%$ followed by endometrial polyp $7 \%$, fine intrauterine adhesions $4 \%$, and cervical stenosis $1 \%$.

Our results agreed with Elbareg et al. (2014) who studied infertile women in whom standard infertility investigations revealed no abnormalities; the results were $33 \%$ of cases had abnormal uterine findings; most of these abnormalities were mild adhesions, small submucous myomas and polyps; the difference between results may be attributed to the larger number of their cases with unexplained infertility.

In a prospective cohort interventional study conducted by Makled et al. (2014) on cases with unexplained infertility evaluated with transvaginal sonography and diagnostic hysteroscopy; based on hysteroscopic findings, $31 \%$ were diagnosed with endometrial polyps, $14 \%$ endometritis, $\quad 15 \% \quad$ endometrial hyperplasia, $6 \%$ submucous myomas, $7 \%$ intrauterine synechiae, $7 \%$ congenital uterine anomalies, $6 \%$ cervical stenosis and $14 \%$ women without any uterine abnormalities. The rate of abnormal hysteroscopic finding in this study is higher than that in our study. This is because it included intrauterine abnormalities which have not been excluded previously by hysterosalpingography or transvaginal sonography. 
Bakas et al. (2014) assessed infertile women by transvaginal sonography (TVS) and hysterosalpingography (HSG) for initial evaluation. If there were no abnormal intrauterine findings, diagnostic hysteroscopy was additionally performed. In $68.2 \%$ findings at hysteroscopy were normal, whereas in $31.8 \%$ hysteroscopy revealed intrauterine lesions (polyps, septa, submucosal leiomyomas, or synechiaes).

Immune-histo-chemical staining is recommended on endometrial specimen to test plasma cell-specific surface antigens CD38 and CD138, in order to confirm the presence of plasma cells, although sometimes the above factors are still inevitable (Song et al., 2017).

A prospective study by Yang et al. (2014) did diagnostic hysteroscopy, endometrial biopsy, and cervical and endometrial Chlamydia infection test. Hematoxylin-eosin staining proved that CE occurred in $12 \%$ of these patients; hysteroscopy had a sensitivity of $16.7 \%$, and specificity of $93.2 \%$ in diagnosing histological CE, and was considered to have a high predictive value of negative result; they considered polyps smaller than $1 \mathrm{~mm}$ in diameter to be "micro polyps", and were often associated with histological CE.

In our data for RIF patients, both hysteroscopy and histology $\mathrm{CE}$ abnormality rate were high; under hysteroscopy, mucous hyperemia, edema, and micropolyps were found in $20 \%$ cases, while histological CE was found in $40 \%$ cases. Hysteroscopy diagnosis for histological CE had a $50 \%$ of sensitivity, and $63.1 \%$ of specificity, which also showed a higher negative predictive value.
Erika et al. (2010) reported cases with CE which, after antibiotic treatment, still had lower implantation rate in the subsequent transfer cycle than the control group, but with similar clinical and ongoing pregnancy rates. Despite these reports that antibiotics can cure pathological CE (absence of plasma cell in endometrium under microscopy), all the studies showed antibiotics cannot improve the ultimate clinical IVF outcomes; some other studies reported that pathological $\mathrm{CE}$, even untreated, does not affect clinical IVF outcomes.

Kasius et al. (2011) concluded that the reproductive outcome after initiation of IVF/ICSI was not found to be negatively affected by histological CE. Therefore endometrial biopsy cannot indicate the overall uterine cavity and endometrial states, since it is based on limited sample collection. On the other hand, embryo implantation may not demand such perfect condition, even pathologically and immune-histo-chemically confirmed CE may not have great effect on implantation.

Hysteroscopy can cover all uterine cavities, which facilitates the observation of endometrial thickness and vessel-filling state so that endometrial receptivity can be evaluated. CE diagnosed through hysteroscopy is likely to be correlated with chronic infection, since antibiotic treatment can clean the occult bacterial infection and increases embryo implantation rate (Yang et al., 2014).

The present study showed that previous IVF failure is the only independent predictor for an intrauterine pathology in women undergoing IVF, and therefore, these women seem to be appropriate candidates for screening by hysteroscopy 
before an IVF attempt. This suggested that each additional IVF failure increased the risk for an intrauterine abnormality, and suggestion for an optimum number of IVF failures after which hysteroscopy should be performed seems inappropriate.

\section{CONCLUSION}

There was a high incidence of intrauterine abnormalities in women with RIF, and hysteroscope was able to efficiently detect and repair occult lesions that were not previously detected by HSG or TVS, significantly improving the pregnancy rate in women with RIF. Even in patients without intrauterine abnormalities, hysteroscope can also promote subsequent pregnancy outcome. Therefore, hysteroscope is of a great value in the evaluation and diagnosis of the endometrial pathology in patients with unexplained recurrent implantation failure, and it should be promoted as a routine examination for RIF women prior to repeat ET.

\section{REFERENCES}

1. Bakas P, Hassiakos D, Grigoriadis C, Vlahos N, Liapis $A$ and Gregoriou $O$ (2014): Role of hysteroscopy prior to assisted reproductive techniques. Journal of Minimally Invasive Gynecology, 21(2): 233237.

2. Coughlan $\mathbf{C}$, Ledger $\mathbf{W}$, Wang $\mathbf{Q}$, Liu $\mathbf{F}$, Demirol A, Gurgan T, Cutting R, Ong K, Sallam H and Li TC (2014): Recurrent implantation failure: definition and management. Reproductive Bio-Medicine Online, 28(1): 14-38.

3. Cicinelli E, Matteo M, Tinelli R, Lepera A, Alfonso $R$, Indraccolo $U$, Marrocchella $S$, Greco P and Resta L (2015): Prevalence of chronic endometritis in repeated unexplained implantation failure and the IVF success rate after antibiotic therapy. Human Reproduction, 30(2): 323-330.
4. Devroey P, Fauser BC and Evian DK (2009): Annual Reproduction (EVAR) Workshop Group. Approaches to improve the diagnosis and management of infertility. Human Reproduction Update, 15(4): 391408.

5. Elbareg A, Essadi FM, Anwar KI and Elmehashi MO (2014): Value of hysteroscopy in management of unexplained infertility. Asian Pacific Journal of Reproduction, 3(4): 295-298.

6. El-Toukhy T, Campo R, Khalaf Y, Tabanelli C, Gianaroli L, Gordts SS, Gordts S, Mestdagh G, Mardesic T, Voboril J, Marchino GL, Benedetto C, AlShawaf T, Sabatini L, SeedPT, Gergolet M, Grimbizis G, Harb $\mathbf{H}$ and Marasamy $A$ (2016): Hysteroscopy in recurrent in-vitro fertilization failure (TROPHY): A multicenter randomized controlled trial. The lancet, 387(10038): 2614-2621.

7. Erika BJM, Hartnett J, Engmann LL, Nulsen JC, Melinda MS and Benadiva CA (2010): Chronic endometritis is a frequent finding in women with recurrent implantation failure after in vitro fertilization. Journal of Fertility and Sterility, 93(2): 437-441.

8. Farahat M, Magdy A and Nagy M (2014): Is hysteroscopy of value for women with previous IVF failure: A randomized clinical trial? Journal of Evidence-Based Women's Health Journal Society, 4 (1): 34-36.

9. Kasius JC, Fatemi HM, Bourgain C, Daisy , Eijkemans RJC, Fauser BC, Devroey $P$ and Broekmans FJM (2011): The impact of chronic endometritis on reproductive outcome. Journal of Fertility and Sterility, 96 (6): 1451-1456

10. Katzorke N, Vilella F, Ruiz M, Krüssel JS and Simón C (2016): Diagnosis of Endometrial-Factor Infertility: Current Approaches and New Avenues for Research. Geburtsh Frauenheilk, 76 (6): 699-703.

11. Makled AK, Farghali MM and Shenouda DS (2014): Role of hysteroscopy and endometrial biopsy in women with unexplained infertility. Archives of Gynecology and Obstetrics, 289 (1):187-192. 
12. Nastri CO, Ferriani RA, Fenning RN and Martins WP (2013): Endometrial scratching performed in the non-transfer cycle and outcome of assisted reproduction: A randomized controlled trial. Ultrasound of Obstetrics and Gynecology, 42(4): 375-382.

13. Sahu L, Tempe A and Gupta $S$ (2012): Hysteroscopic evaluation in infertile patients: A prospective study. International Journal of Reproduction, Contraception, Obstetrics and Gynecology, 1 (1): 37-41.

14. Song D, Feng X, Zhang Q, Xia E, Xiao $Y$, Xie W and Chiu TL (2017): Prevalence and confounders of chronic endometritis in premenopausal women with abnormal bleeding or reproductive failure. Reproductive Biomedicine Online, 36: 78-83.

15. Wadhwa L, Pritam A, Gupta T, Gupta $S$, Arora $S$ and Chandoke R (2015): Effect of endometrial biopsy on intrauterine insemination outcome in controlled ovarian stimulation cycle. Journal of Human Reproductive Sciences, 8 (3): 151-158.

16. Yang R, Du X, Wang $Y$, Song $X$, Yang $Y$ and Qiao J (2014): The hysteroscopy and histological diagnosis and treatment value of chronic endometritis in recurrent implantation failure patients. Archives of Gynecology and Obstetrics, 289 (6): 13631369. 


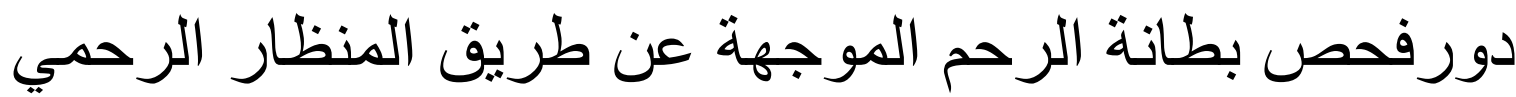

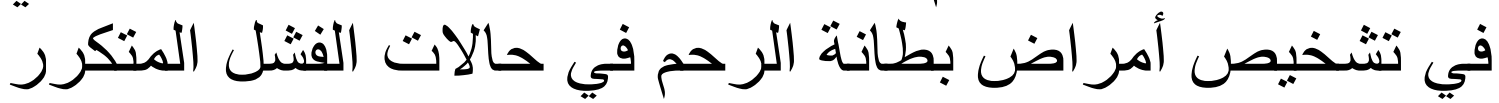

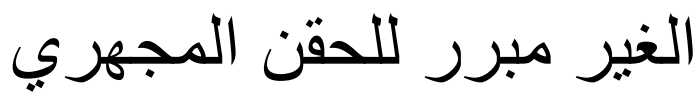
أحمد الثيخ، هشام أبو سنة، محمد حسين

قسم التوليد وأمراض النساء، كلية الطب، جامعة الأزهر

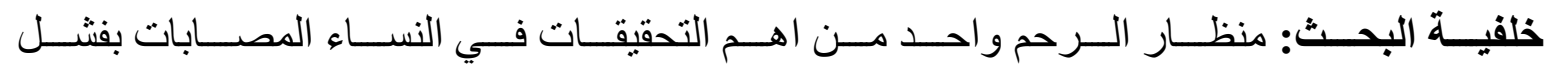

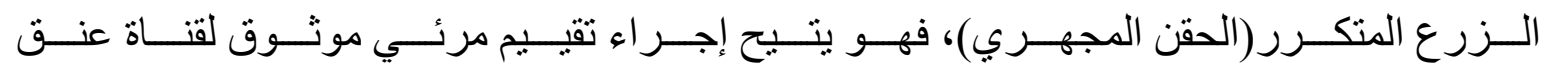

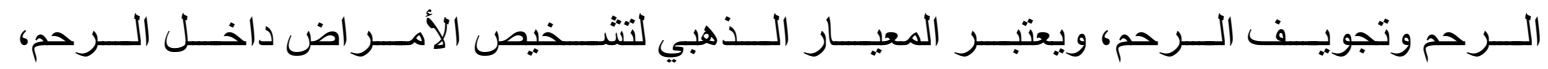
ولايه الحد الأدنى من الاعتلال الجراحي أثناء وما بعد العملية الجراحية.

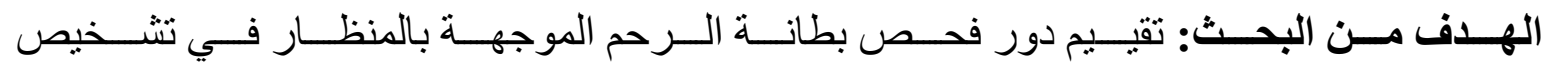

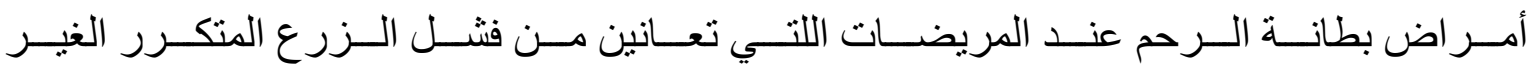

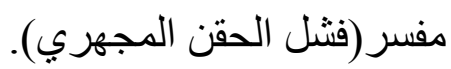

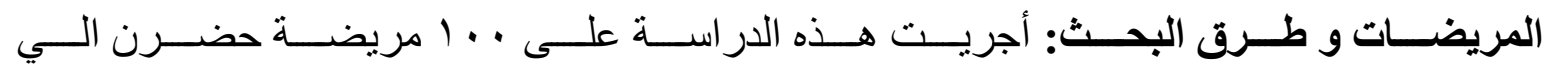

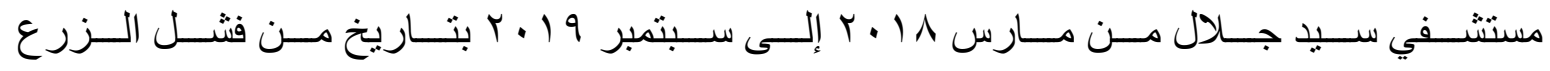

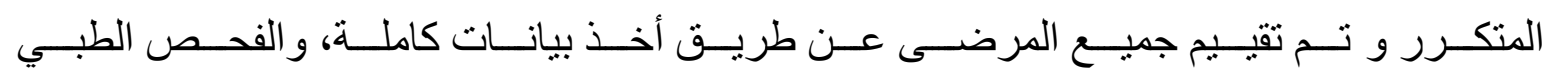

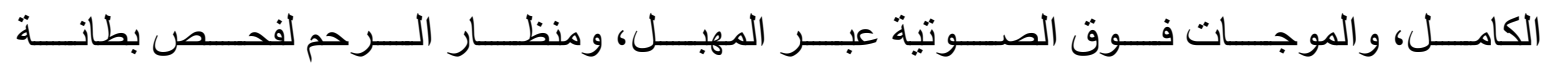

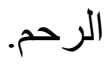

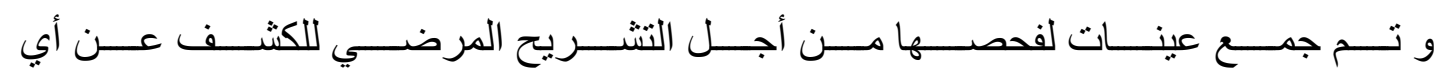
مرض ولنحليله.

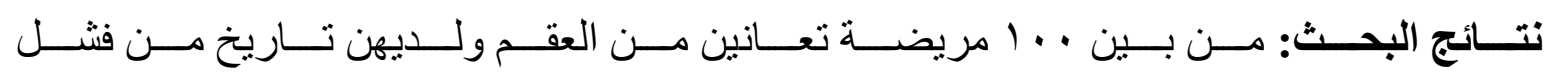

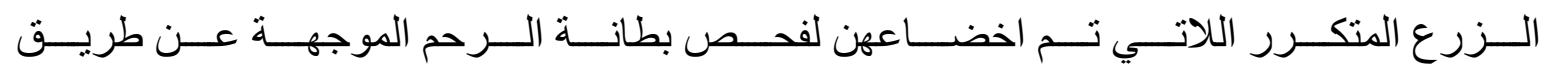

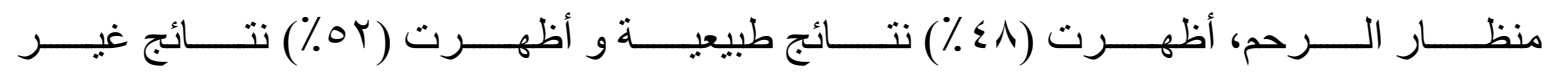

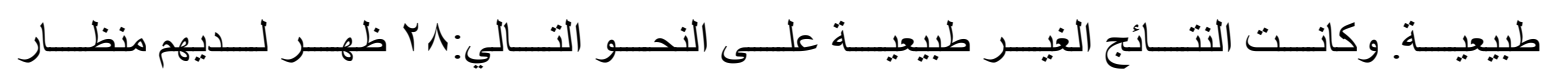

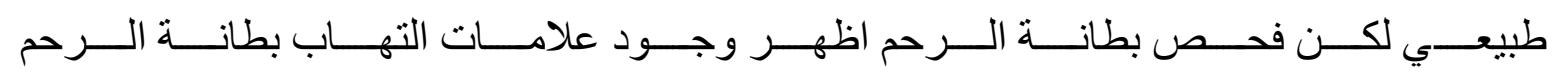

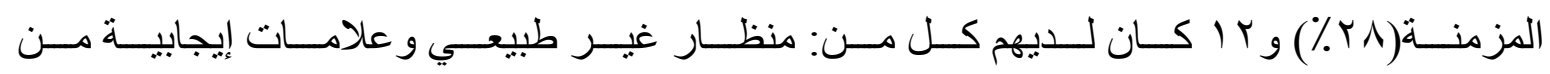




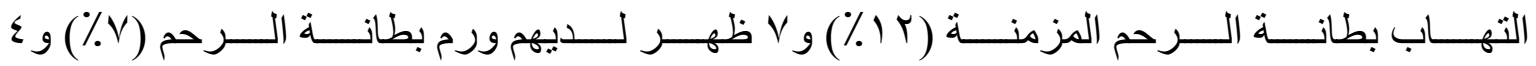

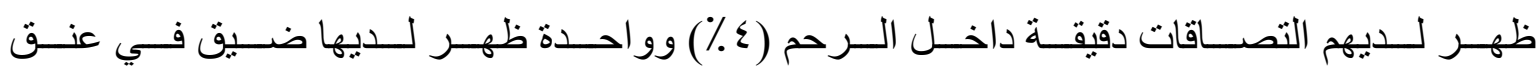

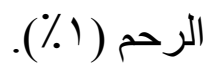

الاســتنتاج: منظـــار الــرحم ذو قيمــة كبيــرة فــي تقيــيم وتشـــيص أمــر اض بطانــة الــرحم لاى المريضات اللاتي تعانين من فشل الزر ع المتكرر الغير مفسر. 